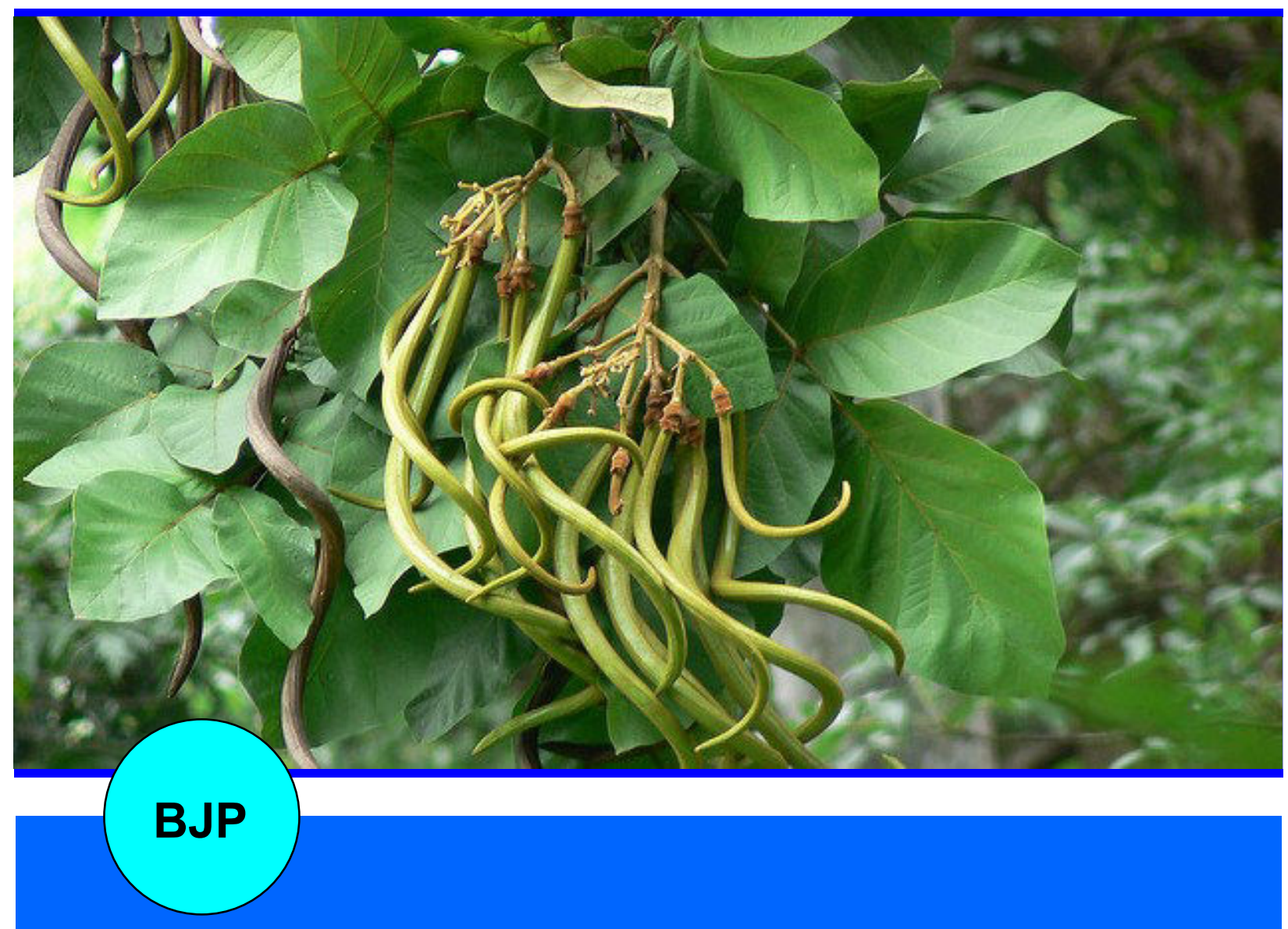

Bangladesh Journal of Pharmacology

Research Article

Phytochemical analysis and antimicrobial study of Fernandoa adenophylla against multidrug resistant urinary tract infection pathogens 
Abstracted/indexed in Academic Search Complete, Asia Journals Online, Bangladesh Journals Online, Biological Abstracts, BIOSIS Previews, CAB Abstracts, Current Abstracts, Directory of Open Access Journals, EMBASE/Excerpta Medica, Google Scholar, HINARI (WHO), International Pharmaceutical Abstracts, Open J-gate, Science Citation Index Expanded, SCOPUS and Social Sciences Citation Index;

\title{
Phytochemical analysis and antimicrobial study of Fernandoa adenophylla against multidrug resistant urinary tract infection pathogens
}

\author{
Abdur Rahim¹, Muhammad Medrar Hussain² and Ihsan Ullah Khan Altaf ${ }^{1}$
}

Department of ${ }^{1}$ Pharmacy and ${ }^{2}$ Microbiology, Abasyn University, Peshawar, Pakistan.

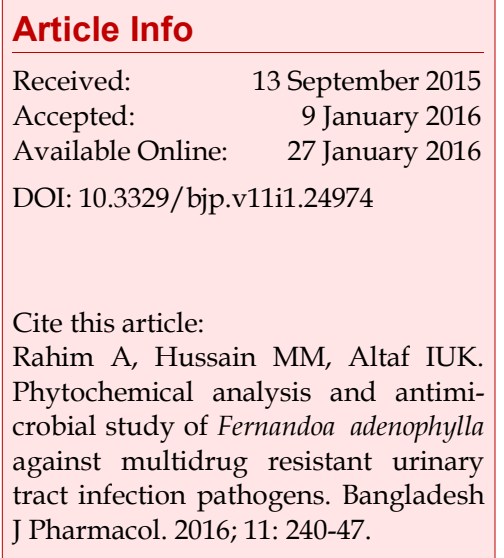

\section{Article Info}

\begin{abstract}
In the present study various solvent extracts from the leaves of Fernandoa adenophylla were screened for their phytochemical and antimicrobial potentials. Preliminary phytochemical screening of leaves extracts showed the presence of alkaloids, glycosides, flavonoids, terpenoids, tannins, steroids, reducing sugars and anthracenes. Fourier transform infrared spectroscopic studies showed the presence of different functional groups for compounds like alcohol, aldehydes and ketones, saturated and unsaturated hydrocarbons, amides, amines, carboxylic acids, esters, and ethers. All the extracts showed significant antibacterial activities when tested against eight multidrug resistant bacterial strains isolated from urinary tract infection patients. It was concluded that the leaves extracts of $F$. adenophylla have several vital phytochemical constituents and significant antibacterial activities against multidrug resistant bacterial strains causing urinary tract infections.
\end{abstract}

\section{Introduction}

The global emergence of multidrug resistant (MDR) bacteria is increasingly limiting the effectiveness of current drugs and significantly causing treatment failures (Hancock, 2005). One of the most common infectious diseases is urinary tract infection (UTI) (Sampson and Gravett, 1999) which has a high tendency of recurrence (Milan, 2006). Most of the studies have shown that UTI pathogens are resistant to the commonly prescribed antibiotics (Mussa-Aisien and Ibadin, 2003). Although many new antibiotics have been introduced, bacterial resistance is also continuously increasing (Hussain et al., 2014), which diverted the researchers towards the development of novel drugs from plant sources, having antimicrobial potentials (Maiyo et al., 2010).

Fernandoa adenophylla, an essential medicinal plant belongs to the family Bignoniaceae consisting of woody plants with approximately 860 species and 82 genera mainly growing in Africa, Central and South America (Lohmann, 2004). It is distributed in South and Southeast Asian regions i.e. Burma, Pakistan, the Andaman Islands, East Bengal and Assam (Olmstead et al., 2009). The leaves and seeds of F. adenophylla are also used as an antimicrobial agent. It is used for the treatment of urinary tract infections as well as anti-diarrheal and anti -diabetic agents (Muhammad et al., 2012). As a folk medicine, it is employed for the treatment of amenorrhoea, night emission, premature ejaculation and skin diseases. It also has antifungal and antiseptic activities (Rahmatullah et al., 2010).

Therefore, the present research work has been designed to investigate the phytochemical constituents and antimicrobial activities of less investigated F. adenophylla against MDR bacterial strains causing UTIs.

\section{Materials and Methods \\ Leaves collection, identification and extraction}


Leaves were collected from the gardens of the University of Peshawar and identified by the Department of Botany, University of Peshawar. The leaves were shade dried and grinded to coarse powder (Sood and Sharma, 2010) using a crusher. Powdered leaves (150 g) were macerated in five different solvents (ethanol, methanol, ethyl acetate, n-hexane and purified water) (Cseke et al., 2006) for 24 hours at room temperature. The supernatant liquids were filtered and collected. The crude extracts were concentrated using rotary evaporator and the solvents were recollected. The concentrated extracts were dried at $60 \pm 5^{\circ} \mathrm{C}$ using water bath. All the extracts were then preserved in separate labeled glass vials and stored at room temperature for further processes.

\section{Phytochemical investigation of extracts}

Qualitative tests were performed for each extract using standard protocols (Kayani et al., 2007; Ayoola et al., 2008) for the presence of different phytochemicals i.e. alkaloids, flavonoids, reducing sugars, terpenoids, saponins, tannins, steroids, glycoside and anthracene.

\section{Fourier transform infrared spectroscopy}

Fourier transformed infrared (FTIR) spectroscopy was carried out using IR Prestige-21 FTIR (Shimadzu, Japan) for the identification and confirmation of different compounds functional groups present in extracts in dried form from $400-4000 \mathrm{~cm}^{-1}$.

\section{Isolation and identification of bacterial strains}

Urine samples from 150 UTI patients were collected from different tertiary care units of Peshawar, Pakistan. These samples were used for isolation of bacterial strains which were identified by specific morphological and biochemical characteristics in the laboratory of the Department of Microbiology, Abasyn University Peshawar. The pathogens isolated were: Escherichia coli, Klebsiella pneumoniae, Citrobacter, Enterobacter, Pseudomonas aeruginosa, Acinetobacter, Providencia, and Methicillin-resistant Staphylococcus aureus (MRSA).

\section{Antimicrobial susceptibility testing for MDR UTI pathogens}

Before evaluating the antimicrobial activity of plant extracts, all the isolated pathogenic microorganisms were tested for MDR profile. The antimicrobial susceptibility was carried out by disc diffusion method using Muller Hinton agar (MHA) as a medium (Ushimaru et al., 2007). The sensitivity of the isolated bacterial strains was tested against 10 commonly used antibiotics in triplicate. All the media plates were incubated for 24 hours at $37^{\circ} \mathrm{C}$.

\section{Antibacterial activity of plant extracts}

Agar well diffusion method (Obeidat et al., 2012; Janovska et al., 2003) was applied for evaluation of antimicrobial activity of the leaves extracts of F. adenophylla. Each extract $(10 \mathrm{mg})$ was dissolved in $1 \mathrm{~mL}$ of dimethyl sulfoxide to get a concentration of $10 \mathrm{mg} / \mathrm{mL}$. On each sterile Muller Hinton agar plat, $100 \mu \mathrm{L}$ of standard inoculum (0.5 MacFarland turbidity standards, 10-6 $\mathrm{CFU} / \mathrm{mL}$ ) of each test bacterial strain was spread with the help of sterilized cotton swabs while sterile borer was used for wells preparation. An amount of $100 \mu \mathrm{L}$ of each extract i.e. ethanolic extract (EE), methanolic extract (ME), ethylacetate extract (EAE), n-hexane extract (nHE) and water extract (WE) was added through micropipette under aseptic conditions into specifically marked wells and then incubated at $37 \pm 2^{\circ}$ $\mathrm{C}$ for 18 hours. Zone of inhibition (ZI) was then measured to the closest point in millimeters $(\mathrm{mm})$ (Bobbarala et al., 2009). The test was performed in triplicate and results were presented as mean \pm standard deviation.

\section{Results}

\section{Phytochemical screening}

The phytochemical screening of F. adenophylla showed the presence of various essential constituents i.e. alkaloids, flavonoids, tannins, saponins, terpenoids, steroids, glycosides, reducing sugars and anthracene (Table I).

\section{Compounds identification through FTIR spectroscopy}

The peaks showed the presence of compounds like alcohol, amides, aldehyde, ketone, carboxylic acid, esters, ethers, amines, imides, amino acids, methyl substituted benzenes, alkyl azo compounds, cylclopentadienyls, organosulfonates and many other aliphatic, cyclic and aromatic compounds (Supplementary data, S1-S5).

\section{Sensitivity of microorganisms}

E. coli was found more sensitive to cefoperazonesulbactam (24 mm), moderately sensitive to gentamicin (12 mm), while it was found resistant to ceftriaxone and moxifloxacin $(8 \mathrm{~mm})$, amoxycillin $(9 \mathrm{~mm})$, tetracycline, nalidixic acid, co-trimoxazole, ciprofloxacin and cefaclor (no ZI). Klebsiella showed more sensitivity to ceftriaxone and cefoperazone-sulbactam (28 mm each) which gradually decreases towards other antibiotics, i.e. cefaclor $(23 \mathrm{~mm})$, amoxycillin $(20 \mathrm{~mm})$, while it was found resistant towards moxifloxacin and gentamicin (10 mm each), tetracycline (09 $\mathrm{mm})$, nalidixic acid, cotrimoxazole and ciprofloxacin $(0 \mathrm{~mm}$ each). The Citrobacter was found more sensitive towards gentamicin $(25 \mathrm{~mm})$ and co-trimoxazole $(24 \mathrm{~mm})$ and showed gradual decrease in sensitivity towards cefoperazone-sulbactam (22 $\mathrm{mm})$, ciprofloxacin and amoxycillin (20 mm each), moxifloxacin (18 $\mathrm{mm})$ and cefaclor $(15 \mathrm{~mm})$ and showed less sensitivity towards tetracycline $(12 \mathrm{~mm})$, while it was resistant to ceftriaxone $(12 \mathrm{~mm})$ and nalidixic acid (no ZI). 
Table I

Phytochemical screening of different extracts of Fernandoa adenophylla

\begin{tabular}{|c|c|c|c|c|c|}
\hline \multirow[t]{2}{*}{ Phytochemicals } & \multicolumn{5}{|c|}{ Plant extracts } \\
\hline & Ethanol & Methanol & Ethyl acetate & n-Hexane & Water \\
\hline Alkaloids & + & + & + & + & + \\
\hline Flavonoids & + & + & - & - & + \\
\hline Tannins & + & + & - & - & + \\
\hline Saponins & + & + & + & + & + \\
\hline Terpenoids & + & + & + & + & + \\
\hline Steroids & + & + & + & + & + \\
\hline Glycosides & + & + & + & + & + \\
\hline Reducing sugars & - & - & - & - & + \\
\hline Anthracene & - & - & - & - & + \\
\hline
\end{tabular}

$(+)=$ Present $(-)=$ Absent

Enterobacter was sensitive to ciprofloxacin $(28 \mathrm{~mm})$, gentamicin $(24 \mathrm{~mm})$ and cefoperazone-sulbactam (20 $\mathrm{mm})$ and was found resistant to ceftriaxone $(13 \mathrm{~mm})$, amoxycillin and tetracycline $(10 \mathrm{~mm}$ each), nalidixic acid, co-trimoxazole, and cefaclor (0 $\mathrm{mm}$ each) according to CLSI (2013) (Table II).

Pseudomonas showed the highest susceptibility profile towards cefoperazone-sulbactam $(28 \mathrm{~mm})$ which gradually decreases towards gentamicin $(24 \mathrm{~mm})$, ciprofloxacin (22 mm), ceftriaxone (20 mm), moxifloxacin (19 mm) and amoxycillin $(18 \mathrm{~mm})$. The organism showed moderate susceptibility to cefaclor $(14 \mathrm{~mm})$, while it was found resistant to co-trimoxazole $(9 \mathrm{~mm})$ and nalidixic acid $(8 \mathrm{~mm})$. Acinetobacter was observed to be more sensitive to co-trimoxazole $(24 \mathrm{~mm})$ and moxifloxacin (23 mm), cefaclor and gentamicin (22 $\mathrm{mm}$ each), amoxycillin $(20 \mathrm{~mm})$, tetracycline $(19 \mathrm{~mm})$ and cefoperazone-sulbactam (18 $\mathrm{mm})$, and showed moderate sensitivity towards ciprofloxacin $(19 \mathrm{~mm})$ and ceftriaxone $(15 \mathrm{~mm})$. The organism was found resistant to nalidixic acid as no ZI was observed. Providencia was found less sensitive as compared to other organisms. Its maximum sensitivity decreases from cefoperazonesulbactam $(20 \mathrm{~mm})$ towards amoxycillin $(15 \mathrm{~mm})$, ciprofloxacin $(14 \mathrm{~mm})$ and showed moderate sensitivity to moxifloxacin (12 mm). According to standard guidelines Providencia was found resistant to tetracycline (9 $\mathrm{mm})$, ceftriaxone, nalidixic acid, co-trimoxazole, cefaclor and gentamicin ( $0 \mathrm{~mm}$ each). MRSA was more sensitive to gentamicin $(20 \mathrm{~mm})$ and cefoperazonesulbactam $(19 \mathrm{~mm})$ and was found less sensitive to ciprofloxacin $(16 \mathrm{~mm})$ and amoxycillin and ceftriaxone (12 $\mathrm{mm}$ each), while it showed resistance to moxifloxacin $(15 \mathrm{~mm})$, tetracycline $(14 \mathrm{~mm})$, nalidixic acid $(10 \mathrm{~mm})$ and cefaclor $(9 \mathrm{~mm})$ and co-trimoxazole (no ZI) (Table II).

\section{Antibacterial activity profile of the plant extracts}

The leaves extracts F. adenophylla were tested against the MDR-UTI pathogens using cefoperazone-sulbactam

Table II

\section{Culture sensitivity of bacterial strains}

\begin{tabular}{|c|c|c|c|c|c|c|c|c|c|c|c|}
\hline \multirow{2}{*}{ SL. No. } & \multirow{2}{*}{ Microorganisms } & \multicolumn{10}{|c|}{ Antibiotic discs with ZI (mm) against test organisms } \\
\hline & & TE & $\mathrm{CRO}$ & NA & SXT & AMC & MXF & CIP & CEC & $\mathrm{CN}$ & SCF \\
\hline 1 & E. coli & $\mathrm{R}$ & 8 & $\mathrm{R}$ & $\mathrm{R}$ & 9 & 8 & $\mathrm{R}$ & $\mathrm{R}$ & 12 & 24 \\
\hline 2 & Klebsiella & 9 & 28 & $\mathrm{R}$ & $\mathrm{R}$ & 20 & 10 & $\mathrm{R}$ & 23 & 10 & 28 \\
\hline 3 & Citrobacter & 12 & 12 & $\mathrm{R}$ & 24 & 20 & 18 & 20 & 15 & 25 & 22 \\
\hline 4 & Enterobacter & 10 & 13 & $\mathrm{R}$ & $\mathrm{R}$ & 10 & 19 & 28 & $\mathrm{R}$ & 24 & 20 \\
\hline 5 & Pseudomonas & 13 & 20 & 8 & 9 & 18 & 19 & 22 & 14 & 24 & 28 \\
\hline 6 & Acinetobacter & 19 & 15 & $\mathrm{R}$ & 24 & 20 & 23 & 19 & 22 & 22 & 18 \\
\hline 7 & Providencia & 9 & $\mathrm{R}$ & $\mathrm{R}$ & $\mathrm{R}$ & 15 & 12 & 14 & $\mathrm{R}$ & $\mathrm{R}$ & 20 \\
\hline 8 & MRSA & 14 & 12 & 10 & $\mathrm{R}$ & 12 & 15 & 16 & 9 & 20 & 19 \\
\hline
\end{tabular}

$\mathrm{TE}=$ Tetracycline $\mathrm{CRO}=$ Ceftriaxone, $\mathrm{NA}=$ Nalidixic acid, $\mathrm{SXT}=$ co-trimoxazole, $\mathrm{AMC}=$ Amoxycillin, $\mathrm{MXF}=\mathrm{Moxifloxacin}, \mathrm{CIP}=\mathrm{Ciprofloxacin}$, $\mathrm{CEC}=$ Cefaclor, $\mathrm{CN}=$ Gentamicin, $\mathrm{SCF}=$ Cefoperazone-Sulbactam, $\mathrm{R}=$ Resistant 
as control. Antimicrobial activity of the extracts i.e. ethanol, methanol, ethyl acetate, n-hexane and water, was evaluated and their potency was quantitatively measured by the presence or absence of ZI (Table III).

The leaves extract of F. adenophylla showed significant antibacterial activity. All the test organisms were found sensitive to these extracts except Klebsiella which showed resistance to EE. The methanolic, ethanolic and water extracts have greater antibacterial activity than ethyl acetate and n-hexane extract.

The ethanol extract of F. adenophylla showed significant activity against all organisms except Klebsiella. The maximum ZI (27.33 $\mathrm{mm})$ for EE was observed against Enterobacter and the lowest ZI $(15.33 \mathrm{~mm})$ was against Providencia. A ZI of $22.66 \mathrm{~mm}$ was observed against Pseudomonas, whereas the ZIs for Acinetobacter, $S$. aureus, Citrobacter and Enterobacter were $20.66 \mathrm{~mm}, 19.33$ $\mathrm{mm}, 17.00 \mathrm{~mm}$ and $27.33 \mathrm{~mm}$ respectively. The ME showed $100 \%$ activity against all the strains. Enterobacter was found most sensitive with ZI of $34 \mathrm{~mm}$ while Providencia was found least sensitive $(14.33 \mathrm{~mm}$ $\mathrm{ZI})$. Activity of ME in terms of ZI against other species were, ZI of $17.33 \mathrm{~mm}$ for E. coli, $19.33 \mathrm{~mm}$ for Pseudomonas, $17.66 \mathrm{~mm}$ for Klebsiella, $19 \mathrm{~mm}$ for both Acinetobacter and MRSA and $17 \mathrm{~mm}$ for Citrobacter. Similarly, EAE also showed variable but significant activities against the tested microorganisms. Enterobacter was the most sensitive among all the strains with ZI of $26.66 \mathrm{~mm}$, whereas Klebsiella was the least sensitive specie with ZI of $12.66 \mathrm{~mm}$. Zone of inhibition for other strains were; $18.33 \mathrm{~mm}$ for E. coli, $18 \mathrm{~mm}$ for Pseudomonas, $15 \mathrm{~mm}$ for both Acinetobacter and Citrobacter, $17 \mathrm{~mm}$ for Providencia and $16.33 \mathrm{~mm}$ for MRSA. The nHE also showed maximum activity against Enterobacter with ZI of $28 \mathrm{~mm}$ while Klebsiella was the least sensitive with ZI of $14.66 \mathrm{~mm}$. E. coli was found the second most sensitive organism with ZI of $18.33 \mathrm{~mm}$ while Pseudomonas (ZI of $16.33 \mathrm{~mm}$ ), MRSA and Citrobacter (ZI of $16 \mathrm{~mm}$ each) exhibited almost similar sensitivity to the extract. Similarly Acinetobacter (ZI of $15.66 \mathrm{~mm}$ ) and Providencia (ZI of $15.33 \mathrm{~mm}$ ) showed approximately similar sensitivity profile to nHE. The WE was more active against Enterobacter with ZI of $23.33 \mathrm{~mm}$ followed by MRSA (20 mm ZI). Gradual decline in the sensitivity of microorganisms to WE was observed from Acinetobacter (ZI $19 \mathrm{~mm}$ ), Pseudomonas (ZI $18.66 \mathrm{~mm})$, E. coli (ZI $18 \mathrm{~mm})$, Citrobacter (ZI 17.66 $\mathrm{mm})$, Providencia (ZI $16.33 \mathrm{~mm})$ to Klebsiella (ZI $16 \mathrm{~mm})$ (Table III).

\section{Discussion}

The current results of phytochemical screening of all extracts of F. adenophylla have shown the presence of alkaloids, flavonoids, tannins, saponins, terpenoids, steroids, glycosides, anthracene and reducing sugars which are also reported previously (Kanchanapoom et al., 2001; Muhammad et al., 2012). Results obtained from the FTIR spectra of the extract have showed the presence of many compounds including aldehydes and ketones, amines, amides, imides, alcohols, carboxylic acids, esters and ethers, amino acids, methyl substituted benzenes, alkyl azo compounds, cylclopentadienyls, organosulfonates and many other aliphatic, cyclic and aromatic compounds, which are not reported in the previous studies to the best of our knowledge as no FTIR data has been found in the literature about $F$. adenophylla.

In the present study eight bacterial strains isolated from urine samples of UTI patients were used to test the antibacterial activities of plant extracts. The bacterial strains were found resistant to most of the antibiotics used in culture sensitivity study. According to standard guidelines (CLSI, 2013; NCCLS, 2012), the organisms were classified as MDR strains. The results showed that E. coli was found to be the most resistant bacteria i.e. to 90\% antibiotics, Enterobacter to 70\%, Klebsiella and Providencia to $60 \%$ and MRSA was found resistant to

\begin{tabular}{|lcc|c|ccc|}
\hline \multicolumn{7}{c|}{ Table III } \\
\hline \multicolumn{7}{|c|}{ Antibacterial activity profile of plant extracts } \\
\hline Organism & Ethanol & Methanol & Ethyl acetate & n-Hexane & Water & Control (SCF) \\
\hline E. coli & 20.33 & 17.33 & 18.33 & 18.33 & 18.00 & 22.00 \\
Klebsiella & 0.00 & 17.66 & 12.66 & 14.66 & 16.00 & 28.00 \\
Citrobacter & 17.00 & 17.00 & 15.00 & 16.00 & 17.66 & 26.00 \\
Enterobacter & 27.33 & 34.00 & 26.66 & 28.00 & 23.33 & 38.00 \\
Pseudomonas & 22.66 & 19.33 & 18.00 & 16.33 & 18.66 & 22.00 \\
Acinetobacter & 20.66 & 19.00 & 15.00 & 15.66 & 19.00 & 22.00 \\
Providencia & 15.33 & 14.33 & 17.00 & 15.33 & 16.33 & 24.00 \\
MRSA & 19.33 & 19.00 & 16.33 & 16.00 & 20.00 & 28.00 \\
\hline
\end{tabular}

Extracts with ZI representing sensitivity or non-sensitivity in $\mathrm{mm}$ 
$50 \%$ antibiotics among all the tested bacterial strains. Citrobacter was resistant to $30 \%$ antibiotics, Pseudomonas to $20 \%$ and Acinetobacter was found resistant to only $10 \%$ antibiotics used in the study. The drug resistance pattern of some of these bacterial strains has also been reported by Ishaq et al. (2014) with little variation, from the same area i.e. Peshawar, Pakistan. In Ishaq et al. (2014) study, E. coli was found $78.6 \%$ resistant, Pseudomonas was 50\%, Klebsiella and Providencia were $85.7 \%$, S. aureus was $50 \%$ and Citrobacter was found $92.8 \%$ resistant to all the tested antibiotics. The variation found in the resistance profile of this study as compared to our study may be due to the nature of antibiotics used and sample.

All the leaves extracts of F. adenophylla were found to have good antibacterial activity. All the organisms under test were found sensitive to these extracts except Klebsiella which showed resistance to ethanolic extract. The ethanolic, methanolic and water extracts showed more antibacterial activity than n-hexane and ethyl acetate extracts. The EE showed maximum activity against Enterobacter ( $27.33 \mathrm{~mm} \mathrm{ZI)} \mathrm{whereas} \mathrm{it} \mathrm{was} \mathrm{found}$ completely ineffective against Klebsiella (no ZI). The ME showed highest activity against Enterobacter (34 mm ZI) and lowest activity against Providencia $(14.33 \mathrm{~mm} \mathrm{ZI})$. The EAE showed maximum activity against Enterobacter (26.66 mm ZI) while it was found least effective against Klebsiella (12.66 $\mathrm{mm}$ ZI). The $\mathrm{nHE}$ also showed optimum activity against Enterobacter $(28 \mathrm{~mm} \mathrm{ZI})$ and showed minimum activity against Klebsiella $(14.66 \mathrm{~mm}$ $\mathrm{ZI})$. The WE showed maximum activity against Enterobacter (23.33 $\mathrm{mm} \mathrm{ZI)}$ and minimum activity against Klebsiella (16 mm ZI). Most of the extracts were very effective against Enterobacter while least effective against Klebsiella. The previous work (Muhammad et al., 2012) on F. adenophylla (leaves and seeds) showed significant antimicrobial activity against different strains of bacteria including B. subtilis, S. aureus, S. epidermidis, $P$. aeruginosa and E. coli. According to Muhammad et al. (2012) study, extracts of F. adenophylla exhibited optimum activity against $S$. aureus and E. coli but showed no activity against $S$. epidermidis. In our study all the extracts showed optimum activity against these microorganisms which is in line with the study of Muhammad et al. (2012). Additionally, our study also covers the MDR bacterial strains in place of normal bacterial strains. There is no previous study on $F$. adenophylla extracts in which MDR strains have been tested. Furthermore, these MDR strains were isolated from the urine samples of UTI patients which give a new dimension to the present study.

In comparison to the antibiotics used in the culture sensitivity, the plants extracts were very active against all of the tested bacterial strains. In the present study, $E$. coli was resistant to $90 \%$ antibiotics but was found sensitive to EE, ME, EAE, nHE and WE. Enterobacter was found resistant to $70 \%$ antibiotics but showed sensitivities towards all extracts. Likewise, Klebsiella was found resistant to $60 \%$ antibiotics whereas it was found sensitive to ME, EE, nHE and WE. Similarly, Providencia and MRSA were resistant to $60 \%$ and $50 \%$ antibiotics respectively but found sensitive to all extracts. Citrobacter, Pseudomonas and Acinetobacter were found resistant to 30,20 and $10 \%$ antibiotics respectively while they were found $100 \%$ sensitive to all the extracts.

\section{Conclusion}

Extracts of F. adenophylla had valuable phytochemical constituents along with significant antibacterial activity against MDR UTI pathogens. Different extracts have different antibacterial activities against MDR bacterial strains which showed the effectiveness of the plant extracts.

\section{References}

Ayoola GA, Coker H, Adesegun SA, Bello AA, Obaweya K, Ezennia EC, Atangbayila T. Phytochemical screening and anti-oxidant activities of some selected medicinal plants used for malaria therapy in South-Western Nigeria. Trop J Pharm Res. 2008; 7: 1019-24.

Bobbarala V, Varahalarao V, Chendrashekar NK. In vitro antimicrobial screening of mangrove plant Avicennia officinalis. Orient J Chem. 2009; 25: 373-76.

Clinical and Laboratory Standards Institute (CLSI). Performance standards for antimicrobial susceptibility testing, twenty-third informational supplement. 2013; 33: M100-S23.

Cseke LJ, Kirakosyan A, Kaufaman, Warber SL, Duke JA, Brielmann HL. Natural products from plants. $2^{\text {nd }}$ ed, USA, CRC Press, 2006.

Hancock EW. Mechanisms of action of newer antibiotics for Gram-positive pathogens. Lancet Infect Dis. 2005; 5: 209-18.

Hussain MM, Ahmad B, Rashid E, Hashim S, Marwat KB, Jan A. In vitro antibacterial activity of methanol and water extracts of Adiantum capillus veneris and Tagetes patula against multidrug resistant bacterial strains. Pak J Bot. 2014; 46: 363 68.

Ishaq MS, Hussain MM, Afridi MS, Ali G, Khattak M, Ahmad S. In vitro phytochemical, antibacterial, and antifungal activities of leaf, stem, and root extracts of Adiantum capillus veneris. Sci World J. 2014; 2014.

Janovska D, Kubikova K, Kokoska L. Screening for antimicrobial activity of some medicinal plants species of traditional Chinese medicine. Czech J Food Sci. 2003; 21: 10710.

Kanchanapoom T, Ryoji K, Kazuo Y. Lignan and phenylpropanoid glycosides from Fernandoa adenophylla. Phytochemistry 2001; 57: 1245-48. 
Kayani AS, Masood A, Achakzai AKK, Anbreen S. Distribution of secondary metabolites in plants of Quetta Balochistan. Pak J Bot. 2007; 39: 1173-79.

Lohmann LG. Bignoniaceae. In: Flowering plants of the neotropics. Smith N, Mori S, Henderson A, Stevenson D, Held S (eds). New York, Princeton University Press, 2004.

Maiyo ZC, Ngure RM, Matasyoh JC, Chepkorir R. Phytochemical constituents and antimicrobial activity of leaf extracts of three Amaranthus plant species. Afr J Biotechnol. 2010; 9: 3178-82.

Milan C. Urinary tract infection and renal scarring. Nat Med. 2006; 12: 636-41.

Muhammad SA, Sajid B, Nabeela TS. Antimicrobial screening of Heterophragma adenophylla extracts and effects of light irradiation. Can J App Sci. 2012; 3: 304-13.

Mussa-Aisien A, Ibadin O. Prevalence and antimicrobial sensitivity pattern in urinary tract infection in febrile under$5 \mathrm{~s}$ at a children's emergency unit in Nigeria. Ann Trop Paediatr. 2003; 23: 39-45.

NCCLS (National Committee for Clinical Laboratory Standards). Performance standards for antimicrobial disc susceptibility tests. $7^{\text {th }}$ ed. Wayne, Pennsylvania, USA, 2012.
Obeidat M, Shatnawi M, Al-alawi M, Al-Zu'bi E, Al-Dmoor H, AlQudah M, El-Qudah J, Otri I. Antimicrobial activity of crude extracts of some plant leaves. Res J Microbial. 2012; 7: 59-67.

Olmstead RG, Michelle L, Zjhra, Lohmann LG, Susan OG, Andrew JE. A molecular phylogeny and classification of Bignoniaceae. Am J Bot. 2009; 96 (9): 1731-43.

Rahmatullah M, Samarrai W, Jahan R, Rahman S, Sharmin N, Miajee EU, Chowdhury MH, Bari S, Jamal F, Bashar A, Azad AK, Ahsan S. An ethnomedicinal, pharmacological and phytochemical review of some Bignoniaceae family plants and a description of Bignoniaceae plants in folk medicinal uses in Bangladesh, Advan. Nat Prod Appl Sci. 2010; 4: 23641.

Sampson JE, Gravett MG. Other infectious conditions in pregnancy. In: High risk pregnancy: Management options. James DK, Steer PJ, Weiner CP, Govik B (eds). 2nd ed. London, WB Saunders, 1999, pp 559-98.

Sood S, Sharma N. Insect growth regulatory activity of Adiantum Capillus-veneris against Plutella xylostella and Aphis craccivora in ethanol and methanol. Res J Agri Biol Sci. 2010; 6: 785-90.

Ushimaru PI, da Silva MTN, Di Stasi LC, Barbosa L, Junior AF. Antibacterial activity of medicinal plant extracts. Braz J Microbiol, 2007; 38: 717-19.

\section{Supplementary Data}

Table SI

IR spectra of ethanol extract for functional groups

\begin{tabular}{|c|c|c|}
\hline IR values (Frequency, $\mathrm{cm}^{-1}$ ) & Bond & Functional groups \\
\hline 3352 & $\stackrel{\mathrm{NH}_{2}}{\mathrm{H}_{2} \mathrm{C}-\mathrm{NH}_{2}}, \mathrm{~N}-\mathrm{H}$ stretch & $1^{\circ}, 2^{\circ}$ amines, amides Diamines \\
\hline 2922 & $\mathrm{Ar}-\mathrm{CH}_{3}, \mathrm{C}-\mathrm{H}$ stretch & Methylbenzenes, Alkanes \\
\hline 2852 & C-H stretch & Alkanes \\
\hline 1683 & $\mathrm{H}_{2} \mathrm{C}=\mathrm{CHOCOR}$ & Vinyl ester \\
\hline 1456 & $\mathrm{R}-\mathrm{CH}_{3}, \mathrm{C}-\mathrm{H}$ bend & Alkanes \\
\hline 1278 & $\mathrm{C}-\mathrm{N}$ stretch & Aromatic amines \\
\hline 1161 & C-N stretch & Aliphatic amines \\
\hline 1033 & $-\mathrm{Oc}^{\mathrm{CH}_{3}}$ & Esters \\
\hline 997 & $\mathrm{H}_{2} \mathrm{C}=\mathrm{CH}$-metal,$==\mathrm{C}-\mathrm{H}$ bend & Cyclopentadienyls, Alkenes \\
\hline 661 & $-\mathrm{C}=\mathrm{C}-\mathrm{H}: \mathrm{C}-\mathrm{H}$ bend & Alkynes \\
\hline
\end{tabular}

Author Info

i Muhammad Medrar Hussain (Principal contact)

' e-mail: medrarbiotech@gmail.com 


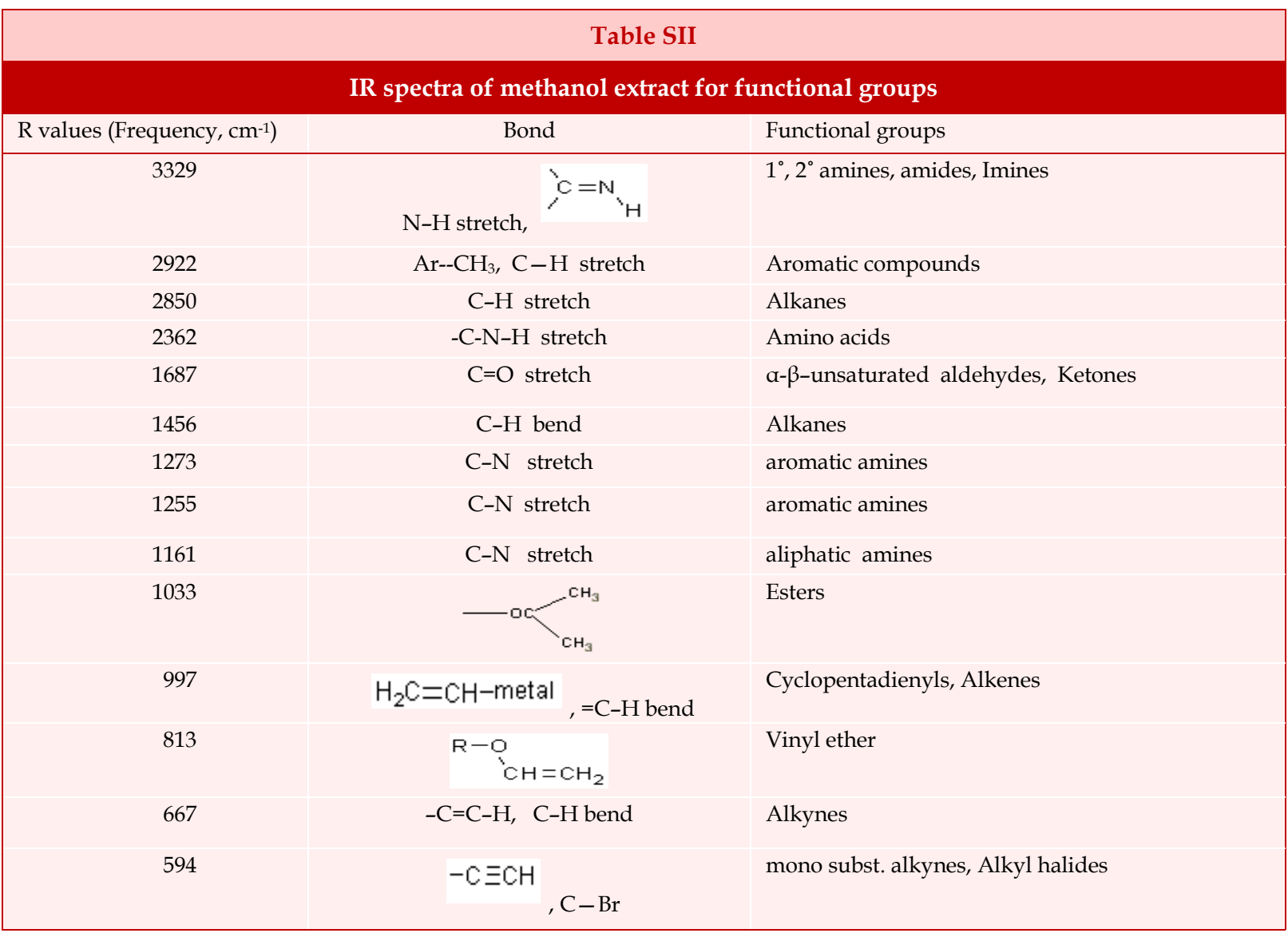

Table SIII

IR spectra of ethyl acetate extract for functional groups

\begin{tabular}{|c|c|c|}
\hline IR values (Frequency, $\mathrm{cm}^{-1}$ ) & Bond & Functional groups \\
\hline 2922 & A.r $-\mathrm{CH}_{3}, \mathrm{C}-\mathrm{H}$ stretch & Methylbenzenes, Alkanes \\
\hline 2850 & C--H stretch & Alkanes \\
\hline 1687 & $\mathrm{H}_{2} \mathrm{C}=\mathrm{CHOCOR}$ & Vinyl ester \\
\hline 1456 & $\mathrm{R}-\mathrm{CH}_{3}$ & Alkanes \\
\hline 1373 & & Branched Alkanes \\
\hline 1317 & $\mathrm{C}-\mathrm{O}$ stretch & carboxylic acids, alcohols, ethers, esters \\
\hline 1274 & C-N stretch & Aromatic amine \\
\hline 1165 & $\mathrm{C}-\mathrm{N}$ stretch & Aliphatic amine \\
\hline 1029 & $-\mathrm{CH}_{3}$ & Esters \\
\hline 997 & $\mathrm{H}_{2} \mathrm{C}=\mathrm{CH}-$ metal,$=\mathrm{C}-\mathrm{H}$ bend & Cyclopentadienyls, Alkenes \\
\hline 661 & $-\mathrm{C}=\mathrm{C}-\mathrm{H}: \mathrm{C}-\mathrm{H}$ bend & Alkynes \\
\hline
\end{tabular}


Table SIV

IR spectra of $\mathbf{n}$-hexane extract for functional groups

\begin{tabular}{|c|l|l|}
\hline IR values (Frequency, $\mathrm{cm}^{-1}$ ) & \multicolumn{1}{c|}{ Bond } & Functional groups \\
\hline 3325 & $\mathrm{~N}-\mathrm{H}$ stretch, $>\mathrm{C}=\mathrm{N}-\mathrm{H}$ & $1^{\circ}, 2^{\circ}$ amines, amides, Imines \\
2953 & Methylbenzenes, Alkanes \\
2916 & $\mathrm{~A}-\mathrm{H}$ stretch & Methylbenzenes, Alkanes \\
2848 & $\mathrm{Ar}-\mathrm{O}-\mathrm{CH}_{3}$ & \\
1732 & $\mathrm{C}=\mathrm{O}$ stretch & Aromatic ethers \\
1712 & $\mathrm{C}=\mathrm{O}$ stretch & Aldehydes, saturated aliphatic \\
1639 & $-\mathrm{C}=\mathrm{C}-$ stretch & Ketones, saturated aliphatic \\
1456 & $\mathrm{R}-\mathrm{CH} \mathrm{H}_{3}, \mathrm{C}-\mathrm{H}$ bend & Alkenes \\
1377 & $-\mathrm{C}-\mathrm{C}-$ & Alkanes \\
1317 & $\mathrm{C}-\mathrm{O}$ stretch & Branched Alkanes \\
1242 & $-\mathrm{C}-\mathrm{H}$ Bend & Alcohols, carboxylic acids, ethers, esters \\
1163 & $\mathrm{C}-\mathrm{N}$ stretch & Cycloalkanes \\
1033 & $-\mathrm{O}-\mathrm{C}-\mathrm{CH} \mathrm{H}_{3}$ & Aliphatic amines \\
1026 & $-\mathrm{C}-\mathrm{C}-\mathrm{H}$ & Esters \\
968 & $=\mathrm{C}-\mathrm{H}$ bend & Cyclohexane \\
777 & $\mathrm{R}-\mathrm{CH}=\mathrm{CH}-\mathrm{R}$ & Alkenes \\
719 & $\mathrm{C}-\mathrm{H}$ bend & Halogen substituted vinylene \\
\hline & & Alkanes \\
\hline
\end{tabular}

\section{Table SV}

IR spectra of water extract for functional groups

\begin{tabular}{|c|c|c|}
\hline IR values (Frequency, $\mathrm{cm}^{-1}$ ) & Bond & Functional groups \\
\hline 3236 & O-H stretch, $\mathrm{H}$-bonded & Alcohols, phenols \\
\hline 1583 & $\mathrm{~N}-\mathrm{H}$ bend & $1^{\circ}$ amines \\
\hline 1558 & C-C stretch (in-ring) & Aromatics, Alkyl azo compounds \\
\hline 1404 & $\mathrm{CH}_{3}-\mathrm{C}=\mathrm{O}$ & Acyclic Ketones \\
\hline 1398 & $\mathrm{C}=\mathrm{O}$ stretch & Aldehydes, saturated aliphatic \\
\hline 1361 & $\mathrm{C}-\mathrm{H}$ rock & Alkanes \\
\hline 1311 & C-O stretch & Alcohols, carboxylic acids, esters, ethers \\
\hline 1280 & C-H wag $(-\mathrm{CH} 2 \mathrm{X})$ & Alkyl halides \\
\hline 1263 & $\mathrm{C}-\mathrm{H}$ wag $(-\mathrm{CH} 2 \mathrm{X})$ & Alkyl halides \\
\hline 1120 & C-N stretch & Aliphatic amines \\
\hline 1093 & & Sat. sec Alcohol \\
\hline 1072 & $-\mathrm{CH}_{2}-\mathrm{OH}$ & Primary alcohol \\
\hline 1043 & & Methyl benzenes \\
\hline 871 & $\mathrm{C}-\mathrm{O}-\mathrm{SO}_{3}$ & Organosulfate \\
\hline 657 & $-\mathrm{C} \equiv \mathrm{C}-\mathrm{H}: \mathrm{C}-\mathrm{H}$ bend & Alkynes \\
\hline 607 & $\mathrm{R}-\mathrm{O}$ & Esters \\
\hline 597 & C-Br stretch & Alkyl halides \\
\hline
\end{tabular}




\section{Your feedback about this paper}

1. Number of times you have read this paper 0

2. Quality of paper Click

3. Your comments

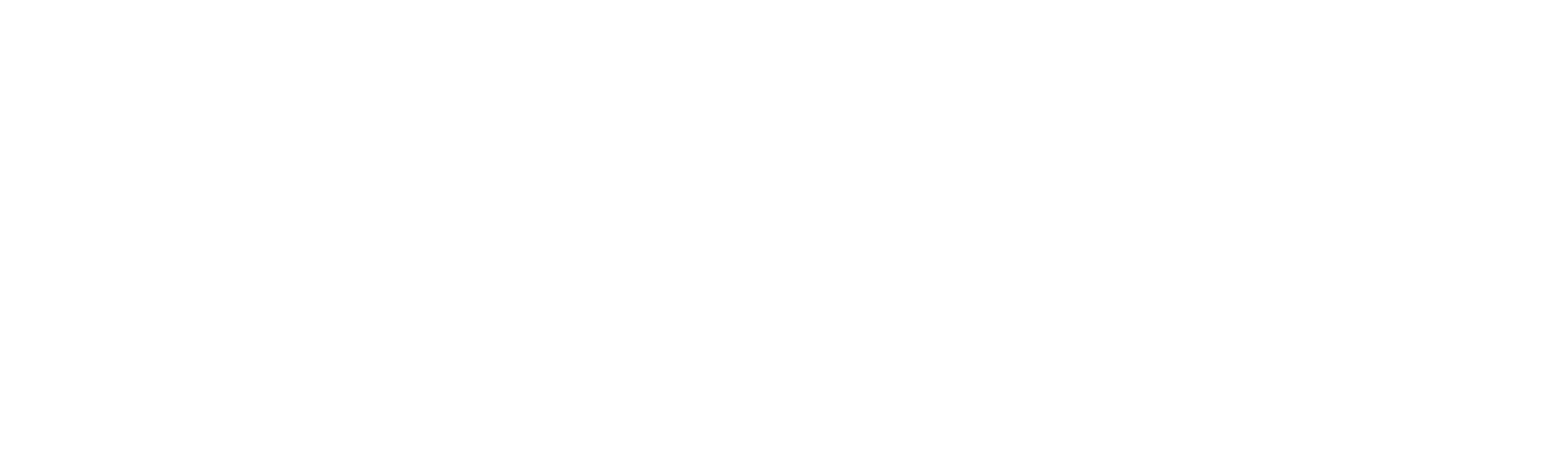

